\title{
Body Composition and Energy Expenditure in Adolescents with Cerebral Palsy or Myelodysplasia
}

\author{
LINDA G. BANDINI, DALE A. SCHOELLER, NAOMI K. FUKAGAWA, LINDA J. WYKES, AND \\ WILLIAM H. DIETZ \\ The Clinical Research Center, Massachusetts Institute of Technology, Cambridge, Massachusetts 02139; \\ Department of Pediatrics, Division of Gastroenterology and Nutrition, New England Medical Center, Boston. \\ Massachusetts 02111; Departments of Medicine and Pediatrics, Harvard Medical School, Boston, Massachusetts \\ 02215; Clinical Nutrition Research Center, University of Chicago, Chicago, Illinois 60637; and Division of \\ Clinical Nutrition, The Hospital for Sick Children, Toronto, Ontario, Canada M5G IX8
}

\begin{abstract}
We measured body composition, resting metabolic rate (RMR), and total energy expenditure (TEE) in a group of adolescents with cerebral palsy (CP) and myelodysplasia $(M)$ aged 13- to 20-y-old using indirect calorimetry and the doubly labeled water method. Fat-free mass (FFM), RMR, and TEE were significantly lower in both the $C P$ and $M$ groups than comparable measurements in a control group of normal adolescent males and females. The ratio of TEE to RMR did not differ between controls and ambulatory $M$ and $C P$ subjects. However, TEE/RMR was significantly lower in the nonambulatory $M$ and $C P$ subjects than in controls $(p<0.01)$. Our data indicate that energy requirements are reduced in both populations because both FFM and activity are decreased. Although energy requirements were decreased in both groups, the relationships between FFM and body weight differed. FFM and body weight were significantly correlated with RMR only in the $M$ group. These data suggest that the type of paralysis in a handicapped population may affect resting energy expenditure. (Pediatr Res 29: 70-77, 1991)
\end{abstract}

\section{Abbreviations}

RMR, resting metabolic rate

TEE, total daily energy expenditure

TBW, total body water

ECW, extracellular water

FFM, fat-free mass

TSF, triceps skinfold

SSSF, subscapular skinfold

SISF, suprailiac skinfold

FQ, food quotient

$\mathrm{CP}$, cerebral palsy

M, myelodysplasia

BMR, basal metabolic rate

NCHS, National Center for Health Statistics

BMI, body mass index

FAO/WHO/UNU, Food and Agricultural Organization/

World Health Organization/United Nations University

Children with physical handicaps are often shorter than healthy children of the same age and sex (1). Reductions in TSF,

Received June 13, 1990; accepted August 20, 1990.

Correspondence and reprint requests: Dr. Linda G. Bandini, Department of Pediatrics, Gastroenterology, and Nutrition, Box 213. New England Medical Center Hospitals, 750 Washington Street, Boston, MA 02111.

Supported by National Institutes of Health Grants 1912211, RR00088 DK26678, and the Thrasher Foundation. stature, and body cell mass are prevalent among children with $\mathrm{CP}$. Whether these changes are a consequence of $\mathrm{CP}$ or chronic undernutrition remains unclear. In contrast, approximately $50 \%$ of children with $\mathrm{M}$ are obese (2). Nonetheless, the short stature and possible alterations in body composition in nonobese and obese children with $\mathrm{M}$ make assessment of nutritional status difficult.

The changes in body composition and physical activity associated with $C P$ and $M$ can be expected to affect energy requirements. Similarly, alterations in energy expenditure might affect body composition. The only reported study that measured TEE in individuals with $\mathrm{CP}$ used heart rate monitoring in conjunction with indirect calorimetry (3). Energy expenditure extrapolated from heart rate monitoring was measured over $24 \mathrm{~h}$ in four subjects and ranged from 1200 to $1850 \mathrm{kcal} / \mathrm{d}$. No comparisons were made with normal controls. Furthermore, in our experience, anxiety during calibration in children with $\mathrm{CP}$ may elevate heart rates. The altered relationship between energy expenditure and heart rate may produce an underestimation of TEE. Nc studies have measured energy expenditure in children or adoles. cents with $\mathrm{M}$.

In our study, we measured TBW and ECW in 13 adolescent: with $\mathrm{CP}$ and 16 adolescents with $\mathrm{M}$. RMR and TEE were measured in 19 of the 29 subjects by indirect calorimetry anc the doubly labeled water method.

\section{MATERIALS AND METHODS}

Subjects. Subjects with CP ranged in age from 15 to $20 \mathrm{y}$ anc included individuals with spastic quadraparesis, diplegia, hemi plegia, and athetosis. Subjects with $M$ ranged in age from 13 tc 24 y. All subjects were recruited from a residential school ir Canton, MA and The Children's Hospital in Boston, MA. All o the subjects or their guardians gave informed written consen before participation in the study. The study was approved by th Institutional Review Boards of the Massachusetts Institute o Technology, Cambridge, MA, Massachusetts Hospital School Canton, MA, and The Children's Hospital, Boston, MA.

Comparisons of body composition and energy expenditur were made with a group of healthy adolescents without handicap who had participated in a study of energy expenditure in obes and nonobese adolescents conducted during the same tim period (4). Because of the small sample of $\mathrm{M}$ males who partici pated in the study of energy expenditure, no statistical compari sons with normal male controls could be made. However, th differences between control and $\mathrm{M}$ males are quite large and th data are presented for comparative purposes. 
Experimental design. Subjects were admitted to the M.I.T. Clinical Research Center between 0830 and $0900 \mathrm{~h}$ on the day of the study. Aside from their handicap, all the subjects were in good health. No food or water was allowed after $2200 \mathrm{~h}$ on the evening before admission.

Body composition and TEE. After admission to the Clinical Research Center, subjects were asked to void and were weighed on an Acme (Oakland, CA) scale accurate to $0.01 \mathrm{~kg}$. After baseline serum and saliva samples were collected, subjects were each given an oral or i.v. dose of water labeled with ${ }^{18} \mathrm{O}$ for the measurement of TBW, or both ${ }^{18} \mathrm{O}$ and deuterium for the measurement of TEE, and a dose of sodium bromide for the measurement of ECW. The dosages were as follows: $0.07 \mathrm{~g} / \mathrm{kg}$ estimated TBW of ${ }^{18} \mathrm{O}$ for TBW only, $0.25 \mathrm{~g}{ }^{18} \mathrm{O} / \mathrm{kg}$ estimated TBW and $0.1 \mathrm{~g}^{2} \mathrm{H} / \mathrm{kg}$ estimated TBW for the measurement of TBW and TEE, and $30 \mathrm{mg} / \mathrm{kg}$ of $\mathrm{NaBr}$ for ECW. In approximately half of the subjects, the dose of $\mathrm{NaBr}$ was $74 \mathrm{mg} / \mathrm{kg}$. Because the analytic precision improved, the dose was decreased to $30 \mathrm{mg} / \mathrm{kg} \mathrm{NaBr}$ in subsequent subjects.

Four $\mathrm{h}$ after administration of the labeled water and bromide, a second sample of serum and/or saliva was obtained to determine TBW and ECW. The following morning, the second void of the day was obtained for the measurement of ${ }^{18} \mathrm{O}$ and ${ }^{2} \mathrm{H}$ enrichment for those subjects participating in the measurement of TEE. These samples were used to start the energy expenditure period. Subjects, staff, or parents were instructed to obtain a urine sample from the subjects on $d 7$ of the 2-wk period. Those subjects who participated in the measurement of TEE returned 2 wk after the initial admission for another outpatient visit. At this time, the second void of the day was obtained to end the energy expenditure period.

Oxygen dilution space $\left(D_{0}\right)$ was calculated from the increase in ${ }^{18} \mathrm{O}$ enrichment of the 4-h serum and saliva relative to predose values as previously described (5). TBW was calculated from $D_{0}$ assuming $\mathrm{TBW}=\mathrm{D}_{\mathrm{O}} / 1.01$. Extracellular water was calculated from the volume of distribution of bromide.

FFM was determined by dividing TBW by 0.73 (6). Ideal body weight was calculated by adding to FFM the average quantity of body fat for age and sex (7). The average quantity of body fat for a 17-y-old was used for those subjects aged 17-24 because Cheek's tables applied only to children and adolescents younger than $17 \mathrm{y}$.

Measurements of skinfold thicknesses were made at the triceps (TSF), biceps, suprailiac (SISF), and subscapular (SSSF) sites with Harpenden calipers (Pfister Import-Export Co., Carlstadt, $\mathrm{NJ}$ ). Circumferences of the head, shoulder, neck, biceps, forearm, chest, waist, pelvis, thigh, knee, calf, and ankle were also measured. Measurements were made in triplicate by a single investigator and the mean of the measurements used for analysis.

$R M R$. Metabolic rate was measured for $30 \mathrm{~min}$ by open circuit indirect calorimetry with a ventilated hood as previously described (8). Subjects were measured $12-14 \mathrm{~h}$ after the last meal and rested in bed for at least $30 \mathrm{~min}$ before the measurement of RMR.

Subjects were familiarized with the hood during a practice session before the actual testing. Two wk later, measurement of metabolic rate was repeated under the same conditions. The intraclass correlation coefficient between the first and second measurement was $r=0.858$ in the CP group and $r=0.941$ in the $M$ group. Mean coefficient of variation was $1.4 \%$ in the $C P$ group and $1.6 \%$ in the $M$ group, suggesting that the measurements were highly reproducible. Because BMR rather than RMR was measured in controls, we measured $B M R$ and $R M R$ on the same day in a group of normal male subjects $(n=9)$. BMR and RMR measured on the same day did not differ significantly (1743 versus $1792 \mathrm{kcal} / \mathrm{d}$ ).

RMR was calculated from measures of oxygen consumption and carbon dioxide production according to Weir's modified formula (9). Accuracy of the method for measuring metabolic rate was $1.4-3.1 \%$ depending on flow rate (8).
Dietary intake. Diet records were obtained for the 2-wk period of the doubly labeled water study. Records were kept by residential staff and parents. In two cases, subjects kept their own diet records. Because of the number of caretakers involved, no formal instruction could be given on how to keep food records. Metabolizable energy intake and the percentages of carbohydrate, protein, and fat in the diet were determined from Handbook no. $456(10)$ and used in the calculation of the FQ.

Analyses. Methods for the isotopic analyses and the calculation of TBW from the ${ }^{18} \mathrm{O}$ dilution space are described elsewhere (5). The mean daily $\mathrm{CO}_{2}$ production rate $\left(\mathrm{r}_{\mathrm{CO}_{2}} \mathrm{~mol} / \mathrm{d}\right)$ was calculated using a modification of Lifson's equation (11):

$$
\mathrm{r}_{\mathrm{CO}_{2}}=(\mathrm{N} / 2.078)\left(1.01 \mathrm{k}_{\mathrm{O}}-1.04 \mathrm{k}_{\mathrm{H}}\right)-0.0246 \mathrm{r}_{\mathrm{H}_{2} \mathrm{O}_{\mathrm{r}}}
$$

where $\mathrm{N}$ is the TBW in mol, $\mathrm{k}_{\mathrm{O}}$ is the ${ }^{18} \mathrm{O}$ elimination rate, $\mathrm{k}_{\mathrm{H}}$ is the ${ }^{2} \mathrm{H}$ elimination rate, and $\mathrm{r}_{\mathrm{H}_{2} \mathrm{O}_{\mathrm{r}}}$ is the estimated rate for isotopically fractionated water loss and is assumed to equal 1.05 $\mathrm{N}\left(1.01 \mathrm{k}_{\mathrm{O}}-1.04 \mathrm{k}_{\mathrm{H}}\right)$. The ${ }^{2} \mathrm{H}$ and ${ }^{18} \mathrm{O}$ isotope elimination rates were calculated by the two-point method using the isotopic enrichment relative to predose and the time difference between collection of the initial and final samples: $k=\left(\ln A \mathrm{PE}_{\mathrm{i}}-\ln \right.$ $\left.A P E_{f}\right) / \Delta t$, where APE is atom percent excess. The turnover rates for ${ }^{18} \mathrm{O}$ and ${ }^{2} \mathrm{H}$ in the $\mathrm{CP}$ subjects were $0.0885 \pm 0.0100$ and $0.0665 \pm 0.0079 / \mathrm{d}$, respectively. In the $M$ group, the turnover rates for ${ }^{18} \mathrm{O}$ and ${ }^{2} \mathrm{H}$ were $0.1154 \pm 0.013$ and $0.0899 \pm 0.0122$ / $\mathrm{d}$, respectively. The use of the two-point method has been validated in humans (12). Use of the dilution spaces 1.01 and 1.04 are validated in our laboratory for lean and obese individuals living in the Boston area. These values, however, have not been validated in a malnourished group in which there may be an excess of ECW. An increase in the ratio of ECW/TBW could decrease the ratio of exchangeable protons and alter the assumption that the ratio of dilution spaces is 1.03 . Assuming that the dilution space ratio is influenced primarily by the protein to water ratio and that the protein to intracellular water ratio is constant, we calculate that the largest change in the ECW/ intracellular water ratio would result in a deuterium dilution space/oxygen dilution space ratio of 1.021 , which would propagate to a $3.5 \%$ error in energy expenditure relative to the value we assumed in our calculations. In four subjects with $M$, the dilution spaces were measured. The mean dilution space ratio was $1.035 \pm 0.033$, which supports the use of our assumed 1.03 ratio rather than the worst case 1.02 calculation given above. However, even if the small alteration in the ratio of dilution spaces as a result of an increase in the ECW/TBW ratio occurs, the absolute values would differ, but not enough to alter the interpretation of the energy expenditure results.

$\mathrm{CO}_{2}$ production and energy expenditure values were average values obtained by dividing the cumulative total by the length of the metabolic period in days. Under conditions where intake and expenditure do not differ by more than $20 \%$, the RQ virtually equals the FQ (13). The FQ is calculated from the proportion of fat, carbohydrate, and protein in the diet. The rate of oxygen consumption $\left(\mathrm{VO}_{2}\right)$ was calculated from the measure of $\mathrm{CO}_{2}$ production from ${ }^{2} \mathrm{H}_{2}{ }^{18} \mathrm{O}$ and the $\mathrm{FQ}\left(\mathrm{FQ}=\mathrm{VCO}_{2} / \mathrm{VO}_{2}\right.$ ). An error of 0.01 in the FQ would be equivalent to a $1 \%$ error in the estimation of TEE (12). The average North American diet has a FQ of 0.85 (14). Deviations greater than $0.03 \mathrm{U}$ are unlikely without significant alterations in the proportion of protein, carbohydrate, and fat in the diet. Furthermore, the mean of measured RQ during the RMR was 0.84 in the CP group and 0.82 in the $\mathrm{M}$ group, confirming the reliability of the calculated $\mathrm{FQ}$. Energy expenditure determined from the doubly labeled water method was calculated from Weir's equation (9) using $\mathrm{CO}_{2}$ production measured by doubly labeled water and $\mathrm{VO}_{2}$ calculated from the FQ.

The concentration of bromide in serum was analyzed by neutron activation (15). Intracellular water was calculated as the difference between TBW and ECW. We assumed the corrected bromide space was equal to the volume of ECW. Corrected 
bromide space (CBS) was calculated using the following formula (16):

$$
\mathrm{CBS}=(\mathrm{Br} \text { dose } / \mathrm{Br} \text { plasma }) \cdot 0.90 \cdot 0.95 \cdot 0.94
$$

where 0.90 is the correction for nonextracellular distribution, 0.95 is the Donnan equilibration factor, and 0.94 is the proportion of water in plasma.

Statistical analysis. Data presented are means \pm SD. Correlations were done by Pearson product moment correlation. Body composition and energy expenditure between normal and $\mathrm{CP}$ or $M$ subjects were compared by an analysis of variance (Dunnetts test for multiple comparisons; Clinfo Inc., Cambridge, MA). Measured and predicted ECW and RMR were compared by paired $t$ test. The intraclass correlation coefficient was calculated according to Zar (17).

\section{RESULTS}

Body composition. All $13 \mathrm{CP}$ subjects were less than the 25 th percentile of height for age and eight of the 13 were less than the 5 th percentile on the NCHS growth charts. Only one subject had a weight greater than the 50th percentile of weight for age and only two had a TSF greater than the 50th percentile expected for age (18). Mean BMI was $13.3 \pm 2.0$ in males and $20.2 \pm 4.5$ in females. These values are considerably lower than expected for age in males but not in females (19). Frequency distributions of height/age, weight/age, TSF/age, and percent body fatness for age in the CP group are presented in Figure 1. Because height was often below the 5th percentile for age and because most of our population was pubertal, we could not determine desirable body weight from the NCHS growth charts in either group Although determination of ideal weight from height for persons with short stature is sometimes done by estimates of weight for height extrapolated to the 50th percentile for age, this approach ignores the changes in body composition associated with puberty.

In the $\mathrm{M}$ group, 15 subjects were below the 25 th percentile of height for age and 13 were below the 5th percentile. Weight for age was less than the 25 th percentile in seven subjects and greater than the 75th percentile in another seven subjects. Twelve of the 16 subjects had a TSF greater than the 75th percentile expected for age (18). Mean BMI was $25.8 \pm 8.7$ in males and $29.0 \pm 3.9$ in females. Frequency distributions of height/age, weight/age, TSF/age, and $\%$ body fat for the $M$ group are presented in Figure 1. Individual subject characteristics are presented in Table 1.

Body composition data for both $\mathrm{CP}$ and $\mathrm{M}$ subjects are presented in Table 2. FFM in the CP group was significantly lower than that in a normal adolescent population (Table 3) (4). Although most of the CP subjects had a low height and weight for age, in eight of the 13 subjects body fatness exceeded the 90th percentile for age (7). In only two CP subjects was body fat as a percent of body weight less than the 5th percentile for age. One of these two (subject no. 13) was the subject with athetosis. The ratio ECW/TBW was $49.8 \pm 3.5 \%$ in males and $49.2 \pm 1.9 \%$ in females and was slightly higher than reported for normal subjects (20).

In the $\mathrm{M}$ group, FFM was significantly lower in the females with $M$ than in the normal population. FFM was lower in the males with $\mathrm{M}$ compared with the control group but the differences were not statistically significant $(p<0.12$, Table 3$)$. Despite the low height and normal weight, percent body fat in all the

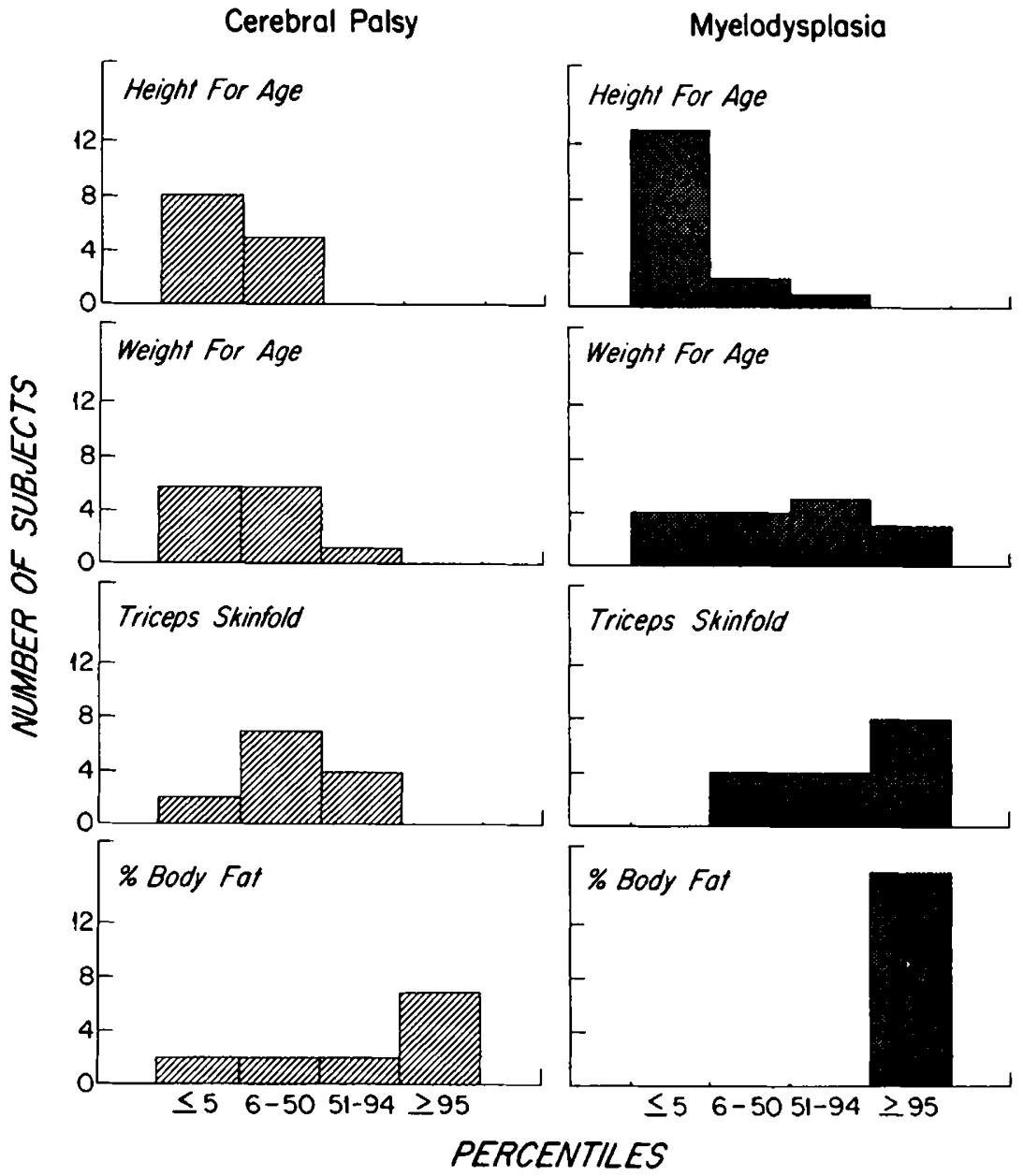

Fig. 1. Left, frequency distribution of height for age, weight for age, TSF for age, and \% body fat for age in adolescents with CP. Right, frequency distribution of height for age, weight for age, TSF for age, and \% body fat for age in adolescents with $M$. 
Table 1. Subject characteristics

\begin{tabular}{|c|c|c|c|c|c|}
\hline Subject & $\begin{array}{l}\text { Age } \\
(\mathrm{y})\end{array}$ & Type & $\begin{array}{c}\text { Ambulatory } \\
\text { status }\end{array}$ & $\begin{array}{c}\mathrm{Ht} \\
(\mathrm{cm})\end{array}$ & $\begin{array}{r}\text { Wt } \\
(\mathrm{kg})\end{array}$ \\
\hline \multicolumn{6}{|c|}{ Females with $\mathrm{CP}$} \\
\hline 1 & 17.6 & $\mathrm{SD}^{*}$ & NA $\dagger$ & 152.0 & 61.8 \\
\hline 2 & 19.1 & SQ & NA & 150.2 & 48.9 \\
\hline 3 & 18.1 & SQ, A & A & 156.3 & 48.2 \\
\hline 4 & 17.7 & SQ & NA & 139.2 & 48.4 \\
\hline 5 & 20.0 & SQ, A & NA & 146.5 & 37.4 \\
\hline 6 & 17.6 & $\mathbf{H}$ & NA & 158.5 & 50.5 \\
\hline 7 & 18.1 & SD & A & 155.5 & 45.6 \\
\hline 8 & 20.8 & SQ & A & 156.7 & 53.3 \\
\hline 9 & 17.6 & SQ & A & 123.0 & 16.7 \\
\hline Mean \pm SD & $18.5 \pm 1.2$ & & & $148.7 \pm 11.4$ & $45.6 \pm 12.6$ \\
\hline \multicolumn{6}{|l|}{ Males with CP } \\
\hline 10 & 15.4 & SQ & A & 164.5 & 35.0 \\
\hline 11 & 19.6 & SQ & A & 151.0 & 31.7 \\
\hline 12 & 15.2 & SQ & NA & 123.0 & 16.2 \\
\hline 13 & 18.7 & $A, S Q$ & NA & 165.0 & 42.2 \\
\hline Mean \pm SD & $17.2 \pm 2.3$ & & & $150.9 \pm 19.7$ & $31.3 \pm 11.0$ \\
\hline \multicolumn{6}{|l|}{ Females with $\mathrm{M}$} \\
\hline 1 & 13.9 & & NA & 148.5 & 63.8 \\
\hline 2 & 14.5 & & A & 162.5 & 91.1 \\
\hline 3 & 23.5 & & A & 135.8 & 67.4 \\
\hline 4 & 16.3 & & A & 150.0 & 59.7 \\
\hline 5 & 17.8 & & A & 147.0 & 62.4 \\
\hline 6 & 15.2 & & A & 138.5 & 45.1 \\
\hline 7 & 18.0 & & NA & 124.0 & 41.4 \\
\hline 8 & 15.9 & & NA & 133.5 & 52.9 \\
\hline 9 & 16.9 & & NA & 135.0 & 44.9 \\
\hline 10 & 18.3 & & NA & 137.3 & 51.2 \\
\hline 11 & 14.0 & & A & 155.0 & 76.2 \\
\hline Mean $\pm S D$ & $16.8 \pm 2.7$ & & & $142.5 \pm 11.1$ & $59.6 \pm 14.9$ \\
\hline \multicolumn{6}{|l|}{ Males with $\mathrm{M}$} \\
\hline 12 & 16.2 & & A & 165.1 & 105.4 \\
\hline 13 & 19.1 & & NA & 164.5 & 83.7 \\
\hline 14 & 17.5 & & A & 160.5 & 48.5 \\
\hline 15 & 18.4 & & A & 156.8 & 51.3 \\
\hline 16 & 17.7 & & NA & 128.7 & 34.5 \\
\hline Mean \pm SD & $17.8 \pm 1.1$ & & & $155.1 \pm 15.1$ & $64.7 \pm 29.0$ \\
\hline
\end{tabular}

* Types of CP: SD, spastic diplegia; SQ, spastic quadraparesis; H, hemiplegia; A, athetosis.

† Ambulatory status: NA, nonambulatory; A, ambulatory.

subjects with $M$ was above the 95 th percentile for age. The ratio of ECW/TBW was $53.7 \pm 4.4$ in the females and $50.7 \pm 3.8$ in the males. Both ratios are higher than reported for normal subjects (20).

Correlation analysis between anthropometric indices and body composition data in the $\mathrm{CP}$ and $\mathrm{M}$ groups was only done for females because of the small number of male subjects. BMI, TSF, SISF, SSSF, and circumferences of biceps, waist, forearm, and knee were highly correlated with measures of body fatness in the CP group (Table 4). In the M group, the correlation of the anthropometric indices with percent body fat did not reach statistical significance. The correlation of body fatness and subscapular thickness was $r=0.55(p<.08)$.

Energy expenditure. Nine $\mathrm{CP}$ subjects and nine $\mathrm{M}$ subjects participated in the study of energy expenditure. Individual results are presented in Table 5.

The relationship of RMR and TEE with FFM was not statistically significant ( $r=0.55$ and $0.47, n=9)$ in the CP group nor was the relationship of FFM with intracellular water $(r=0.55$, $n=9$ ). The lack of correlation may be due to the similarity in FFM among subjects (range 28.9-41.1 kg). In contrast, RMR and TEE were significantly correlated with FFM $(r=0.79$ and $r$ $=0.81$, respectively) in the $\mathrm{M}$ group. RMR predicted from the FAO/WHO/UNU equations (21) did not differ from measured $R M R$ in the $C P$ group $(1270 \pm 131$ versus $1236 \pm 131 \mathrm{kcal} / \mathrm{d})$, but was significantly higher than measured RMR in the M group
$(1388 \pm 145$ versus $1227 \pm 208, p<0.01)$ (Fig. 2). Observed RMR in the $M$ group was not significantly different from that predicted by measures of FFM derived from a control population of normal adolescents (4).

Eight of the nine CP subjects were females with spastic quadraparesis. The 9 th subject was a male who was primarily athetoid. Therefore, we only compared RMR and TEE in the eight CP females with a control group consisting of 10 normal female adolescents in whom we measured BMR and TEE (4). Characteristics of the two groups are presented in Table 6. Data for control and $\mathrm{M}$ males are presented in Table 7.

TEE consists of the energy expended at rest (RMR), activity, and thermogenesis. In this study, RMR and TEE were significantly lower in the $\mathrm{CP}$ and $\mathrm{M}$ females than in adolescents of the same age and sex.

The ratio TEE/RMR is an expression of the amount of energy expended above resting and represents the energy spent on activity and the thermic effect of food. Because we did not find a sex difference in this ratio in a previous study of normal adolescents (4), we combined males and females to compare this ratio among controls, ambulatory, and nonambulatory subjects. The ratio TEE/RMR was significantly lower in the CP and $M$ subjects than in the control group (Table 8). No significant differences existed between controls and ambulatory $C P$ and $M$ subjects. The ratio TEE/BMR was significantly reduced in those $\mathrm{CP}$ and $\mathrm{M}$ subjects who could not ambulate. 
Table 2. Body composition*

\begin{tabular}{|c|c|c|c|c|c|c|}
\hline Subject & TBW (kg) & $\mathrm{ECW}(\mathrm{kg})$ & $\mathrm{ECW} / \mathrm{TBW}$ & FFM (kg) & \% Fat & $\%$ IBW \\
\hline \multicolumn{7}{|c|}{ Females with $\mathrm{CP}$} \\
\hline 1 & 23.6 & 12.3 & 52.0 & 32.3 & 47.7 & 140 \\
\hline 2 & 23.1 & ND & ND & 31.7 & 35.2 & 116 \\
\hline 3 & 26.4 & 12.8 & 48.5 & 36.2 & 33.3 & 101 \\
\hline 4 & 21.1 & 10.4 & 49.3 & 28.9 & 40.4 & 127 \\
\hline 5 & 21.1 & 10.5 & 49.7 & 28.9 & 22.8 & 98 \\
\hline 6 & 23.9 & ND & ND & 32.7 & 35.2 & 116 \\
\hline 7 & 23.0 & 10.4 & 45.6 & 31.5 & 30.9 & 111 \\
\hline 8 & 24.6 & 12.2 & 49.5 & 33.6 & 36.9 & 119 \\
\hline 9 & 10.2 & 5.6 & 55.4 & 14.0 & 16.2 & 93 \\
\hline Mean \pm SD & $21.9 \pm 4.7$ & $10.6 \pm 2.4$ & $50.0 \pm 3.1$ & $30.0 \pm 6.4$ & $33.2 \pm 9.3$ & $113 \pm 15$ \\
\hline \multicolumn{7}{|l|}{ Males with $\mathrm{CP}$} \\
\hline 10 & 21.6 & 11.2 & 51.9 & 29.6 & 15.5 & 105 \\
\hline 11 & 20.0 & 10.3 & 51.4 & 27.4 & 13.6 & 102 \\
\hline 12 & 9.3 & 5.0 & 53.3 & 12.7 & 21.4 & 113 \\
\hline 13 & 30.1 & 13.4 & 44.5 & 41.1 & 2.5 & 90 \\
\hline Mean $\pm S D$ & $20.2 \pm 8.5$ & $10.0 \pm 3.6$ & $50.3 \pm 3.9$ & $27.7 \pm 11.7$ & $13.2 \pm 7.9$ & $102 \pm 10$ \\
\hline \multicolumn{7}{|l|}{ Females with $M$} \\
\hline 1 & 21.1 & ND & ND & 28.9 & 54.7 & 172 \\
\hline 2 & 38.4 & 21.6 & 56.3 & 52.6 & 42.3 & 133 \\
\hline 3 & 21.7 & 11.4 & 52.5 & 29.7 & 55.8 & 170 \\
\hline 4 & 23.7 & 11.1 & 46.6 & 32.5 & 45.6 & 140 \\
\hline 5 & 23.5 & ND & ND & 32.2 & 48.3 & 146 \\
\hline 6 & 21.5 & 10.4 & 48.5 & 29.4 & 34.6 & 117 \\
\hline 7 & 18.4 & 9.7 & 52.9 & 25.2 & 39.1 & 124 \\
\hline 8 & 20.2 & 12.0 & 59.2 & 27.7 & 47.6 & 147 \\
\hline 9 & 16.9 & 9.5 & 56.2 & 23.2 & 48.3 & 147 \\
\hline 10 & 19.6 & 11.2 & 57.1 & 26.8 & 47.6 & 144 \\
\hline 11 & 29.5 & ND & ND & 40.5 & 46.8 & 143 \\
\hline Mean \pm SD & $23.1 \pm 6.0$ & $12.1 \pm 3.9$ & $53.7 \pm 4.4$ & $31.7 \pm 8.3$ & $46.4 \pm 6.1$ & $144 \pm 17$ \\
\hline \multicolumn{7}{|l|}{ Males with M } \\
\hline 12 & 43.9 & 22.1 & 50.3 & 60.1 & 43.0 & 156 \\
\hline 13 & 33.9 & ND & ND & 46.4 & 44.6 & 164 \\
\hline 14 & 26.2 & 13.9 & 53.0 & 35.9 & 26.2 & 119 \\
\hline 15 & 28.3 & 12.9 & 45.5 & 38.8 & 24.4 & 116 \\
\hline 16 & 18.8 & 10.2 & 54.0 & 25.8 & 25.2 & 117 \\
\hline Mean \pm SD & $30.2 \pm 9.4$ & $14.8 \pm 5.1$ & $50.7 \pm 3.8$ & $41.4 \pm 12.8$ & $32.7 \pm 10.2$ & $134 \pm 24$ \\
\hline
\end{tabular}

* Abbreviations: \% Fat, percent body fat; \% IBW, percent ideal body wt; ND, not done.

Table 3. Comparison of body composition of normal adolescents and adolescents with $C P$ and $M$

\begin{tabular}{lrll}
\hline & $n$ & FFM $(\mathrm{kg})$ & \% Fat \\
\hline Females & & & \\
Normal & 10 & $40.9 \pm 5.3$ & $24.7 \pm 7.3$ \\
CP & 9 & $30.0 \pm 6.4^{*}$ & $33.2 \pm 9.3$ \\
M & 11 & $31.7 \pm 8.3^{*}$ & $46.4 \pm 6.1^{*}$ \\
Males & & & \\
Normal & 9 & $49.9 \pm 8.2$ & $14.5 \pm 4.5$ \\
CP & 4 & $27.7 \pm 11.7^{*}$ & $13.2 \pm 7.9$ \\
M & 5 & $41.4 \pm 12.8$ & $32.7 \pm 10.2^{*}$ \\
\hline
\end{tabular}

${ }^{*} p<0.01$ (differences between normals and $\mathrm{CP}$ or $\mathrm{M}$ ).

Table 4. Correlation of anthropometric measures and body fatness in adolescent girls $(n=9)$ with $C P$

\begin{tabular}{lll}
\hline \multicolumn{1}{c}{ Measure } & \multicolumn{1}{c}{$r$} & \multicolumn{1}{c}{$p$} \\
\hline BMI & 0.97 & $<0.0001$ \\
TSF & 0.80 & $<0.01$ \\
SISF* & 0.91 & $<0.01$ \\
Biceps circumference & 0.90 & $<0.001$ \\
Knee circumference & 0.97 & $<0.0001$ \\
Waist circumference & 0.96 & $<0.0001$ \\
Forearm & 0.83 & $<0.01$ \\
SSSF & 0.70 & $<0.05$ \\
\hline$* n=8$ & &
\end{tabular}

$*_{n}=8$.
Table 5. Energy expenditure in adolescents with $C P$ and $M$

\begin{tabular}{cccccc}
\hline Subject & Sex & $\begin{array}{c}\text { RMR } \\
\text { (kcal/d) }\end{array}$ & $\begin{array}{c}\text { TEE } \\
\text { (kcal/d) }\end{array}$ & TEE/RMR & FQ \\
\hline CP & & & & & \\
1 & F & 1362 & 1570 & 1.15 & 0.89 \\
2 & F & 1343 & 1665 & 1.24 & 0.86 \\
3 & F & 1180 & 2512 & 2.13 & 0.88 \\
4 & F & 1252 & 1256 & 1.00 & 0.87 \\
5 & F & 1083 & 1607 & 1.48 & 0.87 \\
6 & F & 1176 & 1567 & 1.33 & 0.88 \\
7 & F & 1053 & 1727 & 1.64 & 0.87 \\
8 & F & 1221 & 1962 & 1.61 & 0.85 \\
13 & M & 1452 & 1757 & 1.21 & 0.83 \\
M & & & & & \\
5 & F & 1205 & 1847 & 1.53 & 0.85 \\
6 & F & 1101 & 1738 & 1.58 & 0.87 \\
7 & F & 1078 & 1090 & 1.01 & 0.88 \\
8 & F & 1428 & 1704 & 1.19 & 0.86 \\
9 & F & 1046 & 1328 & 1.27 & 0.84 \\
10 & F & 1136 & 1148 & 1.01 & 0.92 \\
11 & F & 1596 & ND $\dagger$ & ND & ND \\
14 & M & 1468 & 2126 & 1.45 & ND \\
15 & M & 1258 & 1868 & 1.48 & 0.86 \\
16 & M & 954 & 1461 & 1.53 & 0.89 \\
\hline
\end{tabular}

${ }^{*} \mathrm{~F}$, fermale; $M$, male.

$+N D$, not done. 


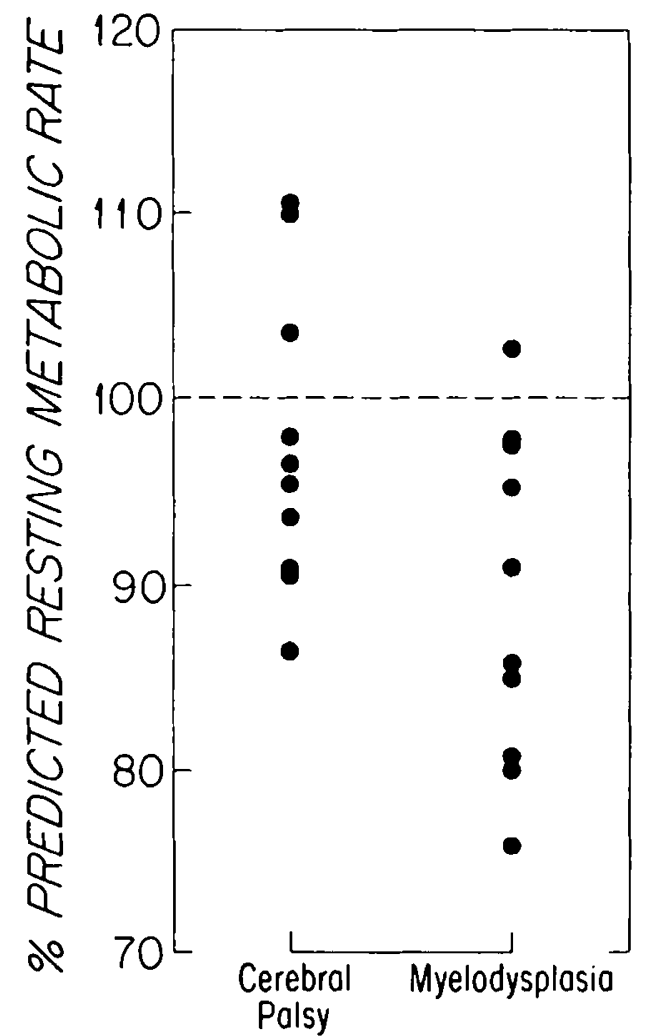

Fig. 2. Individual RMR as a percentage of that predicted from the FAO/WHO/UNU equation.

Table 6. Comparison of body composition and energy expenditure in normal adolescent girls and those with $C P$ and $M$

\begin{tabular}{lccc}
\hline & Normal & CP & M \\
\hline$n$ & 10 & 8 & 7 \\
Age $(\mathrm{y})$ & $14.1 \pm 1.0$ & $18.6 \pm 1.2 \dagger$ & $16.6 \pm 1.6 \dagger$ \\
$\mathrm{Ht}(\mathrm{cm})$ & $161.6 \pm 6.2$ & $151.9 \pm 6.0^{*}$ & $138.6 \pm 9.9 \dagger$ \\
$\mathrm{Wt}(\mathrm{kg})$ & $54.8 \pm 8.8$ & $49.3 \pm 6.9$ & $53.4 \pm 12.1$ \\
$\mathrm{FFM}(\mathrm{kg})$ & $40.9 \pm 5.3$ & $32.0 \pm 2.4 \dagger$ & $29.3 \pm 5.7 \dagger$ \\
$\%$ Fat & $24.7 \pm 7.3$ & $34.3 \pm 8.1^{*}$ & $44.6 \pm 5.5 \dagger$ \\
$\mathrm{RMR}(\mathrm{kcal} / \mathrm{d})$ & $1431 \pm 100$ & $1209 \pm 111 \dagger$ & $1227 \pm 258 \dagger$ \\
TEE $(\mathrm{kcal} / \mathrm{d})$ & $2421 \pm 481$ & $1733 \pm 370 \dagger$ & $1476 \pm 328 \dagger$ \\
\hline
\end{tabular}

$* p<0.05$.

$+p<0.01$.

Table 7. Comparison of body composition and energy expenditure in adolescent males with and without $M$

\begin{tabular}{lcc}
\hline & Normal males & Males with M \\
\hline$n$ & 9 & 3 \\
Age $(\mathrm{y})$ & $14.8 \pm 1.7$ & $17.9 \pm 0.5$ \\
Wt $(\mathrm{kg})$ & $58.6 \pm 11.0$ & $44.8 \pm 9.0$ \\
Ht $(\mathrm{cm})$ & $169.3 \pm 10.2$ & $148.7 \pm 17.4$ \\
FFM $(\mathrm{kg})$ & $49.9 \pm 2.7$ & $33.5 \pm 6.8$ \\
\% Fat & $14.5 \pm 1.5$ & $25.3 \pm 0.9$ \\
RMR $(\mathrm{kcal} / \mathrm{d})$ & $1749 \pm 174$ & $1227 \pm 258$ \\
TEE $(\mathrm{kcal} / \mathrm{d})$ & $3201 \pm 507$ & $1818 \pm 335$ \\
\hline
\end{tabular}

\section{DISCUSSION}

Most adolescents with $\mathrm{CP}$ and $\mathrm{M}$ are shorter than their peers and often below the 5 th percentile of height for age $(22,23)$. In $\mathrm{CP}$, chronic undernutrition may be produced by low energy intakes or increased energy expenditure. Obesity is frequently found in $M(2)$ and may result from a decrease in energy requirements. Thus, these two groups lie at opposite ends of the
Table 8. Effect of ambulation on energy expenditure

\begin{tabular}{lcc}
\hline & $n$ & TEE/RMR \\
\hline Normal females and males & 19 & $1.76 \pm 0.25$ \\
CP & 3 & $1.79 \pm 0.29$ \\
$\quad$ Ambulatory & 6 & $1.23 \pm 0.16^{*}$ \\
$\quad$ Nonambulatory & & \\
M & 4 & $1.51 \pm 0.06$ \\
$\quad$ Ambulatory & 5 & $1.20 \pm 0.22^{*}$ \\
$\quad$ Nonambulatory &
\end{tabular}

${ }^{*} p<0.01$.

clinical spectrum and provide an excellent opportunity to compare and contrast anthropometric indices and energy metabolism.

We assessed nutritional status in individuals with both handicaps using standard measures obtained from the NCHS growth charts and skinfold thickness and compared these findings with direct measures of body composition. Indices based on height and weight for age and TSF suggested chronic undernutrition in the $C P$ population. In the $M$ group, indices based on height for age suggested a chronically undernourished population, although those based on weight for age and TSF suggested that at least half of the population was overweight.

Measures of body composition did not agree consistently with height, weight, or TSF data in either the CP or M group. The observed ratio ECW/TBW in both CP and M males and females was higher than that reported in the literature (20). Increases in ECW have been associated with malnutrition (20), but in our subjects TBW as a percentage of body weight was not increased.

Body fatness was calculated from TBW measurements and was greater than the 95th percentile for age in half of the $\mathrm{CP}$ subjects and all of the $\mathrm{M}$ subjects. However, observed $\mathrm{ECW}$ was significantly greater $(p<0.0001)$ than that predicted by regression equations based on TBW (24). Our measures of body fatness determined from ${ }^{18} \mathrm{O}$ dilution assumed a hydration factor of 0.73 for FFM. The increase in the ECW/TBW ratio may be due to a loss of body cell mass or an increase in the hydration factor. In the $M$ group, the increased adiposity may be responsible for the increase in the ECW/ICW ratio (25). An increase in the hydration factor would diminish calculated FFM; body fat would appear increased. An alternate explanation for the CP group is that tonic muscle contractures depleted body glycogen. Decreased glycogen would reduce intracellular water and increase the ECW/TBW ratio.

Because of the discrepancies between the use of height, weight, TSF and body composition data to determine nutritional status, we examined the relationship of several other anthropometric indices with body fatness calculated from the body composition data. Body fat was calculated by subtracting FFM from body weight. The percent of body weight as fat was equivalent to body fat/body weight $\times 100$. In the adolescent CP females, TSF, SSSF, SISF and waist and knee circumference correlated significantly with percent body fat. These correlations suggest that anthropometric indices may be useful to assess nutritional status in individuals with $\mathrm{CP}$.

The lack of a significant correlation between skinfold thickness and body composition in the $\mathrm{M}$ group suggests that fat distribution may be altered in individuals with this type of paralysis. $M$ patients often lack movement in their lower extremities. Because fatness increases over paralyzed limbs (26), TSF measures may be less valid indicators of body fatness than lower extremity skinfolds. Because $\mathrm{M}$ individuals may have an altered fat distribution, regression equations specific to this population should be developed. Larger samples should be examined in both the $\mathrm{CP}$ and $\mathrm{M}$ groups to determine the best predictor of body fatness. Furthermore, these data emphasize the importance of specific regression equations for different groups to achieve valid information regarding the use of anthropometry to assess nutritional status. 
Energy expenditure. RMR expressed in $\mathrm{kcal} / \mathrm{d}$ was significantly lower in adolescents with $\mathrm{CP}$ or $\mathrm{M}$ than in a control group of normal adolescents, suggesting that energy requirements are reduced. The expression of the data, however, requires normalization for body size and composition.

In normal adolescents, FFM correlates with BMR (4). Lack of a significant correlation between RMR and FFM in CP may be due to several factors. The most likely explanation is that our sample size was small and the range of FFM in the group too narrow for an adequate correlation analysis. Second, our subjects consisted of a heterogeneous group with varying types of $\mathrm{CP}$. Spasticity may have been so variable that the relationship of RMR to FFM was obscured. Although all subjects were in a resting state, increased muscle tone of $\mathrm{CP}$ subjects may have prevented a state of muscle relaxation comparable to normal subjects. The effect of spasticity on RMR can be estimated from the slopes of the regression FFM:RMR in normal and CP subjects. However, a comparison of the relationship of RMR:FFM between normal controls and CP subjects could not be done in this study because the CP sample size was so small.

The significant correlation observed between FFM and RMR in the $M$ group and the lack of a difference between the observed RMR and that predicted from a regression equation from normal adolescents suggests that the relationship of FFM and RMR is not altered in the $\mathrm{M}$ group. This finding supports the hypothesis that the decrease in RMR reflects a decrease in FFM rather than altered metabolic activity.

The differences in the relationship of FFM and RMR between $\mathrm{CP}$ and $\mathrm{M}$ suggest that the type of paralysis may affect basal energy expenditure. For example, variable spasticity associated with $\mathrm{CP}$ may confound any relationship between FFM and $\mathrm{RMR}$, whereas the consequences of $\mathrm{M}$ are more homogenous. In the $M$ group, the decrease in FFM is associated with an increase in body fat. This alteration in body composition may explain the lack of reliability of the FAO/WHO/UNU equation to estimate $R M R$ in the $M$ group.

TEE expressed in $\mathrm{kcal} / \mathrm{d}$ was significantly lower in $\mathrm{CP}$ and $\mathrm{M}$ adolescents. Part of the decrease reflects decreased RMR. The other major determinant of energy needs appears to be ambulation. Lack of ambulation in both CP and $M$ significantly reduced nonbasal energy expenditure. These data suggest that the energy cost of daily living activities in ambulatory subjects was comparable.

Our energy expenditure data, however, do not support the previous reports of massive energy requirements in $\mathrm{CP}$ subjects $(27,28)$. The lack of formalized instructions in diet record keeping and the number of caretakers involved in the recording made estimates of metabolizable energy intake unreliable. Because of the oral motor problems associated with $\mathrm{CP}$, much of the food provided may be lost to spillage, which may produce overestimates of energy expenditure. Oral motor impairment, when superimposed on a CNS insult, may limit food intake and exacerbate the growth retardation in this population (29). Because our studies were not prospective, we do not know whether the short stature in $\mathrm{CP}$ subjects was associated with chronic undernutrition or whether more aggressive nutritional intervention at an early age would have altered growth.

The factorial approach suggested by FAO/WHO/UNU appears to be a useful guide to approximate energy needs in the $C P$ population. BMR calculated from the FAO equations will yield results $\pm 10 \%$ of individual needs. For nonambulatory adolescents with $\mathrm{CP}$, estimated daily energy expenditure is 1.2 times BMR. The highest ratio appeared in an ambulatory female with both spastic quadraparesis and athetosis. For ambulatory adolescents, estimated TEE ranges from 1.6 to 2.1 times BMR. Our data suggest that the factorial approach should be used as a guideline for patients with $\mathrm{CP}$, and energy intake should be adjusted based on changes in weight and fatness.

The FAO/WHO/UNU equation appears to overestimate RMR by a mean of $15 \%$ in the $M$ group. After adjusting predicted RMR for this overestimation and using activity factors representative of our subjects ( 1.2 for nonambulatory subjects and 1.5 for ambulatory), the factorial approach presented by the FAO/WHO/UNU may be used as a guideline to determine energy requirements and energy intakes needed for weight loss in adolescents with $\mathrm{M}$. Nonetheless, the potential error introduced by these assumptions may be considerable. Therefore, careful monitoring of body weight and frequent reevaluation of the diet are crucial.

Our data suggest that children with $\mathrm{M}$ are clearly at risk for obesity. Short stature and a decrease in FFM and activity all contribute to a reduction in TEE in the adolescent with $M$. In the females, TEE differed by a mean of $1000 \mathrm{kcal} / \mathrm{d}$ between controls and $M$ subjects. Low energy expenditure limits the energy deficit during hypocaloric treatment and makes weight reduction extremely difficult.

Although we did not study children, the reduction in expenditure and the significant prevalence of obesity in adolescents with $M$ suggest that weight gain and energy intakes should be monitored carefully during childhood. In four girls aged 5-10 y with $M$ (data not presented), mean percent body fat was $46.2 \pm 1.7 \%$, indicating that they were already obese. TEE measured in the 10 -y-old was only $895 \mathrm{kcal} / \mathrm{d}$. Although preliminary, these data suggest that energy requirements in young children with $M$ are already significantly lower than those of normal children. Successful prevention requires parental awareness of the reduced energy requirements. Dietary habits and caloric intakes should be evaluated in children whose weight exceeds the 50 th percentile for age and nutrition intervention provided as needed.

In summary, our data suggest that the energy needs of adolescents with either $M$ or $C P$ are significantly lower than normal age peers. In the $\mathrm{CP}$ group, anthropometry to determine nutritional status may be as accurate as body composition providing that standards specific for this population are developed. Energy requirements appear to be primarily affected by ambulation. The effect of spasticity on RMR in CP and the best measure of body composition in $M$ warrant further investigation. Differences in energy needs should be considered in the dietary management of these groups of patients to prevent malnutrition.

Acknowledgments. The authors thank the staff at the Clinical Research Center at M.I.T. for their assistance with the study, Sheila Bell, R.N.P for her help organizing the study at the Massachusetts Hospital School, Peter Taylor for the isotopic analysis, Dr. Paul Pencharz at the Hospital for Sick Children and Dr. R.G.V. Hancock at the Slowpoke Reactor Facility, University of Toronto for the neutron activation analysis, and Pamela Peak for her assistance with the preparation of the manuscript.

\section{REFERENCES}

1. Pryor HB, Thelander HE 1967 Growth deviations in handicapped children, an anthropometric study. Clin Pediatr (Phila) 6:501-511

2. Hayes-Allen MC, Tring GC 1973 Obesity: another hazard for spina bifida children. Br J Prev Soc Med 27:192-195

3. Berg L, Alsson T 1970 Energy requirements of school children with cerebral palsy as determined from indirect calorimetry. Acta Paediat Scand [Suppi] 204:71-80

4. Bandini LG, Schoeller DA, Dietz WH 1990 Energy expenditure in obese and nonobese adolescents. Pediatr Res 27:198-203

5. Schoeller DA, Van Santen E, Peterson DW, Dietz WH, Jaspan J, Klein PD 1980 Total body water measurement in humans with ${ }^{18} \mathrm{O}$ and ${ }^{2} \mathrm{H}$ labeled water. Am J Clin Nutr 33:2686-2693

6. Pace N, Rathbun EN 1945 Studies of body composition. III. The body water and chemically combined nitrogen content in relation to fat content. J Biol Chem 158:685-691

7. Cheek DB 1968 Human Grownh. Lea and Febiger, Philadelphia, pp 474-500

8. Bandini LG, Schoeller DA, Edwards J, Young VR, Oh SH, Dietz WH 1989 Energy expenditure during carbohydrate overfeeding in obese and nonobese adolescents. Am J Physiol 256:E357-E367

9. Weir JB 1949 New methods for calculating metabolic rate with special reference to protein metabolism. J Physiol (Lond) 109:1-9

10. Nutritive Values of American Food in Common Units. Agriculture Handbook, N456 (Cat. no. A 76:456). 1975 United States Dept. of Agriculture, Washington, DC 
11. Schoeller DA, Ravussin E, Schutz Y, Acheson KS, Baertschi P, Jequier E 1986 Energy expenditure by doubly labeled water: validation in humans and proposed calculation. Am J Physiol R823-R830

12. Schoeller DA 1988 Measurement of energy expenditure in free living humans by using doubly labeled water. J Nutr 118:1278-1289

13. Black AE, Prentice AM, Coward WA 1986 Use of food quotients to predict respiratory quotients for the doubly-labelled water method of measuring energy expenditure. Hum Nutr Clin Nutr 40C:381-391

14. United States Department of Agriculture 1980 Current Food Consumption Practices and Nutrient Sources in the American Diet. 1980 US Government Printing Office, Washington, DC

15. Vaisman N, Pencharz PB, Koren G, Johnson JK 1987 Comparison of oral and intravenous administration of sodium bromide for extracellular water measurements. Am J Clin Nutr 146:1 -4

16. Bell EF, Ziegler EE, Forbes GF 1984 Letter to the editor. Pediatr Res 18:392393

17. Zar JH 1984 Biostatistical Analysis. Prentice Hall, Philadelphia, pp 323-325

18. Frisancho RA 1981 New norms of upper limb fat and muscle areas for assessment of nutritional status. Am J Clin Nutr 34:2540-2545

19. Cronk CE, Roche AF 1982 Race and sex-specific reference data for triceps and subscapular skinfolds and weight/stature. Am J Clin Nutr 35:347-354

20. Shizgal HM 1987 Nutritional assessment with body composition measurements. J Parenter Enteral Nutr 11:425-475
21. World Health Organization 1985 Energy and Protein Requirements. Report of a joint FAO/WHO/UNU expert consultation. World Health Organization, Geneva

22. Dietz WH 1987 Nutritional requirements and feeding of the handicapped child. In: Grand RJ, Stuphen JL, Dietz WH (eds) Pediatric Nutrition, Theory and Practice. Butterworth, Boston, pp 387-392

23. Tobias JS, Saturen P, Larios G, Posniak AO 1961 Study of growth patterns in cerebral palsy. Arch Phys Med Rehabil 42:475-481

24. Forbes GB 1987 Human Body Composition: Growth, Aging, Nutrition and Activity. Springer-Verlag, New York, pp 139-150

25. Pierson Jr RN, Wang J, Yang Mu, Hashim SA, Van Itallie TB 1976 The assessment of human body composition during weight reduction: evaluation of a new model for clinical studies. J Nutr 106:1694-1701

26. Lee MMC 1959 Thickening of the subcutaneous tissues in paralyzed limbs in chronic hemiplegia. Hum Biol 31:187-193

27. Phelps WM 195i Dietary requirements in cerebral palsy. I Am Diet Assoc 27:869-870

28. Eddy TP, Nicholson AL, Wheeler EF 1965 Energy expenditure and dietary intakes in cerebral palsy. Dev Med Child Neurol 7:377-386

29. Krick J, Van Duyn MS 1984 The relationship between oral-motor involvement and growth: a pilot study in a pediatric population with cerebral palsy. J Am Diet Assoc 84:555-569 